\title{
Norm structure, diffusion, and evolution: A conceptual approach
}

\author{
Abstract: Norms are one of the most widely studied topics of contemporary International \\ Relations scholarship. Norms scholars have created an extensive theoretical and empirical \\ literature to identify, describe and analyze the emergence, diffusion and effect of norms in the \\ international system. However, this scholarship is inconsistent in how it treats state choice and \\ norm diffusion: in particular, it is divided between theories which emphasize continuity and \\ those which allow for change in the process of norm adoption and implementation.
}

This article suggests that the problem can be remedied through a closer examination of the structure of norms themselves. It first shows that the prevailing understanding of contemporary international norms is that they have a tripartite structure, consisting of a problem, a value, and a behavior. These structural components can be combined to create norms as traditionally understood, the article also proposes a new concept: a "norm cluster," which allows for multiple combinations of conceptually interlinked but distinct values and behaviors, offering multiple acceptable solutions to similar and interlocking problems. The actors which adopt a norm cluster, rather than a single norm or set of norms, may be recognized as a family group: although no cluster adopter need perfectly re-enact the choices of others, the resulting variation in outcomes is accepted as "close enough." The article argues that focusing on norm components and clusters, rather than on single norms as currently understood, allows for a more precise understanding of how principle-based action diffuses and evolves in the international system.

Keywords: norms, international relations theory, constructivism, diffusion 


\section{Introduction}

What exactly should a democracy look like? How should actors fight climate change? What should states do to deal with past human rights violations? Each of these issues is the basis for an international norm, or at the very least a set of related norms which coalesce around a general issue. However, there is no international treaty telling us exactly how states should design a participatory democracy. There are many ways to fight climate change, and the various international protocols offer states a number of options to fulfil their emissions reduction targets. Transitional justice as a field remains highly contextual, even as certain aspects have crystallized and become incorporated into international law. Amidst this confusion, however, scholars, policymakers, and activists are certain that these norms exist.

These are all examples of variation within international norms: in definitions, in options, and in actual state practice. For the norms above, and for others, there seem to be a lot of acceptable options for "appropriate behavior." How is this variation in the content of a norm created, and why is acceptable to parties who judge norm adoption and compliance? The notion of acceptable variation is especially troubling, because there is also variation across norms: not all norms are so large and fuzzy. Some norms are seemingly clear and succinct, and stand alone, while others are multifaceted, interlocking, and open to interpretation. States and other actors also have different reactions to different types of norms, sometimes viewing them as malleable, and other times as fixed. Why?

This article attempts to answer the questions above by examining the conceptual structure of the contemporary international norm. Norms research is as varied as the phenomenon it is attempting to understand. However, the field is experiencing a disconnect between different pieces of the norms puzzle: current definitions, and the conceptual structure they imply, do not 
appear to allow for the incredible variety of norms, their diffusion and evolution, and state practices regarding these norms which are observed in the real world.

This article first investigates the structure of international norms as currently conceived and the implications of that structure for norm diffusion, arguing that norms' dual qualities of stability and flexibility create a conflict between their supposedly singular construction and the outcomes of various norm diffusion processes. This conflict results in a failure to amalgamate knowledge on norm evolution, diffusion, and effects, and sometimes even to reach agreement on the content of specific norms themselves. To address this problem, I propose a new conceptual structure for understanding principled action in the international system, a "norm cluster." I then examine several real-world examples of norm clusters, and point to the separate diffusion of norm components as the principal enabler of norm clusters as opposed to single norms or sets of norms. The article concludes with implications of the norm cluster concept for the wider study of norms, norm diffusion, and norm evolution.

\section{Norm function and structure}

Norms can be thought of as "shared intersubjective understandings that make behavioral claims (Checkel, 1997)," or "standards of appropriate behavior (Finnemore and Sikkink, 1998). ${ }^{1 "}$ They "are used to make demands, rally support, justify action, ascribe responsibility, and assess the praiseworthy or blameworthy character of an action" (Checkel, 1997). In the international system they are also understood as "providing solutions to coordination problems, reducing transaction costs, [and] providing a language and grammar of international politics"

\footnotetext{
1 There is no single accepted standard definition of norms, but a number of closely related and widely used definitions exist. See also (Chayes and Chayes, 1995; Jepperson, Wendt and Katzenstein, 1996, p. 54).
} 
(Cortell and Davis, 2000, pp. 65-66). With these diverse functions, norms can be understood to have both constitutive and constraining aspects (Checkel, 1997). The interaction of these two functions creates a norm's conceptual structure, which consists of three components: problem, value, and behavior.

Social constructivists such as Wiener $(2008,2014)$ and Wendt (1999) argue that norms have "constitutive" functions: they create categories of actors and actions, and determine those actors' identities and interests. Norms create meaning through the construction of intersubjective (i.e. collectively held) understandings of who and what things are. This meaning includes whether or not the item in question (whether it be tangible, such as a reduced carbon footprint, or intangible, such as accountability or reconciliation) is valued. ${ }^{2}$ The assignment of value is subjective, but important: it is these value-laden items which define problems, because material or social facts must be understood in relation to the values of a society in order to be seen as good or bad (Wendt, 1999, pp. 111-112). A fact becomes problematized if it is interpreted in such a way that its existence negatively impacts the attainment or continued practice of something that is valued, thus necessitating some form of corrective behavior. In other words, no principled action is possible if "underlying conditions in world affairs" are not defined as problems, in relation to values, by actors holding those values (Carpenter, 2007, p. 112).

On the other hand, scholars also perceive norms as having a "constraint" function: they define "acceptable" justifications for behavior. If a state wishes to pursue a specific behavior to address a defined problem, acceptance by other actors of the legitimacy or appropriateness of

\footnotetext{
2 These values have also been sometimes referred to as principles, foundational norms, or metanorms (Sandholtz, 2007; Wiener, 2008, p. 67) in the sense that they provide overarching duties of conduct in order to provide or uphold them across issue areas, but are not necessarily operationalized, or applied to any specific behaviors, until the problem is clearly defined. While the level of abstraction, specificity, or potential range of application may vary across terms, the fundamental nature of something of "value" persists.
} 
that behavior depends on how it is publicly justified. Actors rarely seek to publicly justify behavior based on pure self-interest; usually actions are justified by reference to widely held values (Risse, 2000, p. 17). Public acceptance of that action as legitimate depends at least partially on whether external actors believe the embedded causal story (Stone, 1989): that it will actually operationalize the given (appropriate) value and therefore address the problem. The value which identifies a problem also limits the behaviors which are appropriate to solve it.

Hurrell and MacDonald (2012, p. 61) argue that determining "appropriate behavior" depends on the interplay of these two processes. Norm-building is therefore the process of constructing a bridge between the constitutive and the constraint functions of norms such that a combined statement is reached: "Given this problem, my values dictate this behavior."3 This statement gives a norm an intrinsic tripartite structure. First, a norm presupposes a problem, which is the issue to be addressed. Second, the norm includes a value. It is the enjoyment or attainment of something "good" or the avoidance of something "bad" and, as such, gives moral weight to the problem. Third, a norm enjoins a particular behavior: the action to be taken to address the given problem which allows the actor to better express or practice the value. In short, a problem inhibits the full enjoyment of a value, and necessitates a corrective behavior. Figure 1, below, formalizes these components into a logical structure.

\section{If [problem], [value] suggests [behavior].}

Figure 1: Formal model of the tripartite structure of contemporary international norms.

\footnotetext{
${ }^{3}$ Risse, Ropp and Sikkink (Risse and Sikkink, 1999) suggest that through a process of pressure or coercion leading to behavior change, and then habituation and socialization (the spiral model), a behavior could also lead eventually to a value.
} 
Richard Price's account of the anti-landmines norm (1998) provides a concrete example of the interaction of these three components. The norm is the nexus between the problem (the existence of landmine technology), a value (the ethical need to discriminate between civilians and soldiers in warfare), and a behavior (the non-use of a certain type of weapon). Because landmines cannot distinguish between civilians and soldiers and will explode no matter who triggers them, they are a problem for societies that value civilian-soldier discrimination. Framing the norm in terms of its underlying structure results in the following directive: "If [landmines], [civilian discrimination in warfare] suggests [non-use].”

This structure underlies a number of the basic definitions of norms in use in International Relations scholarship. It is clearest in March and Olsen's "simple behavioral proposition":

Most of the time humans take reasoned action by trying to answer three elementary questions: What kind of a situation is this? What kind of a person am I? What does a person such as I do in a situation such as this? ... Fitting a rule to a situation is an exercise in establishing appropriateness (March and Olsen, 2008, p. 690).

Similarly, Fearon argued that norms translated into ordinary language take the form "Good people do (or do not do) X in situations A, B, C..." (1999, p. 27). "Good people" is indicative of a value: what makes people "good" is linked to what they think is valuable or important. "Situations A, B, C" is the problem determined by actor values. To "do (or do not do) $\mathrm{X}$ " is to engage in the behavior indicated by the interaction of the problem and values. Goertz (2003, pp. 34-38) echoes this structure, but alters the order of logic, when he frames norms as a "moral syllogism": Major Premise, Minor Premise and Conclusion. The major premise is the value. The minor premise is the problem, or specific situation to which the value must be applied, and the conclusion is the behavior which follows. 
Lastly, the logic of argumentation (Risse, 2000) also suggests a tripartite structure for norms and normative decision-making. The forum in which this occurs is one of "argumentative rationality,"

A communicative process in which actors collectively deliberate over their assumptions about the world, the values they share, how those assumptions and values should apply to their behavior, and whether particular behaviors actually conform with abstract standards (Payne, 2001, p. 783).

The topics of discussion for actors engaging in this process are the constituent pieces of the norm itself: their assumptions about the world (problem), shared values, and how they should act based on those assumptions and values (behavior). The last piece, whether the particular accurately reflects the abstract, acts as a final confirmation that the norm created reflects both intersubjective understanding of the norm's components and the embedded causal story.

This conceptualization of norm structure does not address a key piece of some norm definitions: identity. The full definition of a norm according to Finnemore and Sikkink (1998) is "an appropriate standard of behavior for an actor with a given identity [italics added]". Although identity figures prominently in constructivist theory, including much work on international norms, it is not included in the conceptual structure of norms above because it is not necessary. This is for three reasons.

First, because identity as a social category can be based on different types of attributes (role, physical characteristic, value, etc.) (Wendt, 1999, pp. 224-230), different identities based on these attributes will affect the process of norm-building in inconsistent ways. As an example, "democratic identity" includes values which define problems (such as citizen participation and freedom of speech), but it also implies procedural and institutional features which make some behaviors justifiable (elections, public debates) and others not (suppression of political 
opposition, rule by executive fiat). Depending on which type of attribute an identity relies on, different parts of a norm's construction are affected. This suggests that norm-building by interrogating the problem-value nexus and the value-behavior nexus without first determining which one is influenced by an identity is sufficient to reach a conclusive normative statement.

Second, identity is a multifaceted concept which is not necessarily determinative of single standards of appropriate behavior. It is well understood that actors may have multiple identities whose relative importance may vary across issues (Wendt, 1999, p. 230; Lebow, 2016, p. 2), but even a single identity can itself be incredibly complex and changing (Fearon, 1999, p. 15): the attributes understood to form part of a democratic identity have changed over time, as our beliefs about partial versus universal enfranchisement have expanded or as the democratic peace has become more carefully theorized. Therefore, identity cannot be consistently applied to normative reasoning without engaging the more specific questions which are already part of the conceptual structure detailed above.

Lastly, the addition of identity as a necessary component of norms precludes the possibility of universal norms which apply regardless of identity. If every identity includes the same problem-value nexus and the same possible behavior justified as a corrective, identity ceases to be of analytical utility in determining the content of a norm. ${ }^{4}$

\footnotetext{
${ }^{4}$ Identity instead acts as a conditioning agent for the whole tripartite structure, but is not necessarily determinative: the agent's identity, or whichever identity is prominent at the time, may affect whether or not one sees a given context as a problem, which value[s] which might be "activated," and the potential range of behaviors which are possible to enact and effective at achieving the chosen value given the context. Given different identities, the content of a norm may change, but its underlying structure will not.
} 


\section{Diffusion and the dual quality of norms}

Norms may have a single conceptual structure but, as Wiener $(2007,2008,2009)$ argues, they have a "dual nature": they are both stable and flexible. Nowhere is this more apparent than in the process and outcomes of norm diffusion, in which states will variously interact with norms as they are (stable) or change them, either purposefully or accidentally (flexible). This duality presents a problem for norms researchers studying the diffusion and evolution of norms throughout the international system, as it complicates the relationship between actor (norm adopter), process (diffusion mechanism), and object (the norm itself).

Wiener identifies two major, and opposing, qualities of norms: first, that norms are stable social facts, and second, that they are continuously contested and reconstituted. The logics of consequences and appropriateness, she argues, view norms as stable: once established, their existence as social facts shapes state behavior (either "norm following" or norm rejection). A third logic, that of argumentation, views norms as flexible only until their intersubjective meaning is established ("norm-setting"). Lastly, Wiener proposes a fourth logic: contestedness. The basic assumption of the logic of contestedness is that norms are both stable and flexible: while norms' content and validity may be challenged at any time, recognition that a norm exists still structures behavior. In turn, that behavior may influence the content and meaning of the norm, leading to further contestation and different types of behavior (2008, pp. 37-58).

As norms diffuse throughout the world, and are adopted by states, they display both these qualities of stability and flexibility. Each trait offers a different outcome of norm diffusion, with its own form of variation in states' principled decisions: first, that norms diffuse exactly according to their original contents of problem, value and behavior (stability) and, second, that a 
norm's content may actually change in the process of diffusion and adoption (flexibility). ${ }^{5}$ As the logic of contestedness suggests, if norms are both stable and flexible at the same time, then different states should react differently to the norms presented to them: some should adjust their behavior based on the norm's existing meaning, while others should seek to adapt that meaning. Diffusion outcomes over the whole group of involved actors, then, should sometimes lead to stability, and sometimes change. Reflecting this duality, there are two sets of norm diffusion theories which focus on either of these two outcomes.

\section{Fused norm diffusion and continuity}

Some studies of international norm diffusion implicitly assume that the tripartite structure of norms is stable, or fused together, such that norm diffusion is also assumed to include the diffusion of all three parts of a single norm: value, problem, and behavior. One consistent finding among diffusion scholars, for example, is that "entities that share similar cultural attributes tend to adopt the same practices...Actors negotiating a complex set of political choices regard the actions of actors with perceived common interests as a useful guide to their own behavior" (Elkins, Simmons 2005, 45). To rephrase the above comment using norm structure, those states with similar identities, or "cultural attributes" (including values), will have similar interests (problems) and will generally adopt similar policies (behaviors). March and Olsen also suggest that the process of diffusion thus works through the construction of "typologies of similarity"(2008, pp. 693-695). ${ }^{6}$ Faced with norm choice, the precedent of the state which is

\footnotetext{
${ }^{5}$ A norm's structure, however, does not change: that there must be a combination of problem, value, and behavior remains the same even as the exact problems, values and behaviors themselves may change in response to contestation.

${ }^{6}$ This is contrasted with multiple realizability, in which no diffusion occurs and states react in similar manners but completely independently to similar circumstances, such as natural disasters (Elkins \& Simmons, 2005; Wendt, 1999, 165).
} 
most similar to the one currently making the decision is the most likely to be imitated. In essence, all three parts of a norm's structure interact to create diffusion of a fused norm.

Other scholars focus not on states' similarities but on the contents of norm themselves and how they are portrayed by norm entrepreneurs. Antje Wiener argues that norms by their very nature have "recognizable ... prescriptions for behavior (2008, p. 42; see also Checkel, 2001, pp. 182-183)" meaning that if norms diffuse, actors know what they have to do. Payne theorizes persuasion by arguing that the frame of a normative debate is a key factor in an actor's ability to persuade others. He argues that a norm's frame "provide[s] a singular interpretation of a particular situation and then indicate[s] appropriate behavior for that context" (2001, p. 39). A frame's utility in norm diffusion therefore lies in the creation of shared meaning: providing a problem-value interpretation to understand the situation at hand with respect to an actor's interests and goals (Bleich, 2002), which then suggests behavior. All three of the norm's components are understood as a combined unit, and diffuse together.

However, this is clearly not the whole story, even with respect to fused norm diffusion: much of the recent work on norms and decision-making examines the interaction of multiple related, but still fused, norms within a set. ${ }^{7}$ From within this group actors will choose the single norm or norms which they determine as most appropriate, but the assumption of fused norm components remains: the options available for choice remain composed of the same three elements for all parties.

\footnotetext{
${ }^{7}$ Or other similar term, implying more or less internal structure. Finnemore and Sikkink (1998) refer to both bundles and institutions, and Betts and Orchard (2014) echo their use of bundles. Crocker (1999) uses framework, while Tiemessen (2011) talks about normative structure; Acharya (2004) uses hierarchy, although this is more common among international legal scholars. Regimes tend to refer to the specific formal and informal structures which organize and regulate normative behavior in the international system, such as "the human rights regime" (Donnelly, 1986). Cortell and Davis (2000) refer to two "sets" of "normative structures".
} 
For example, Finnemore and Sikkink are careful to note the difference between single norms and norm groups: "norm definition isolates single standards of behavior, whereas institutions emphasize the way in which behavioral rules are structured together and interrelate" (1998, p. 892) to determine which standard of behavior to choose. Similarly, a normative framework or structure (Crocker, 1999; Tiemessen, 2011) acts as a guide for actors to determine their behavioral choices based on where their specific circumstances fall within a larger collection of norms. A regime also includes rules and decision-making procedures (Krasner, 1983), which guide states to pre-determined behaviors based on the regime's embedded or explicit principles (values). In each of these formulations, a single outcome from among a group of stable norms (problem, value and behavior) must eventually be decided based on each state's own particular context as interpreted by the institution, framework, or regime which applies the norm set to specific states and contexts. At the end of these decision processes, each final norm choice remains stable and identifiable: even though multiple options exist, their contents remain fixed and it is relatively easy to determine which final option(s) a state has actually chosen.

When more than one option can be chosen from within the set (but not all options must be chosen), as with certain institutions such as the European Union, this combination of stability and variation continues. Schimmelfennig et. al. (Holzinger and Schimmelfennig, 2012; Leuffen, Rittberger and Schimmelfennig, 2012; Schimmelfennig, 2014) describe the situation as one of "policy differentiation" (and with respect to the EU, "differentiated integration"), where the increasing heterogeneity of potential new adopters means that not all actors are able (or willing) to undertake all options pursued by their predecessors, but still subscribe to the general goals of the larger norm set. Rather than reject the entire norm set, actors undertake only a portion of its 
included options. While these norms are the same for all who agree to them (preserving object continuity), not all actors undertake the same bundle of options (variation).

\section{Partial norm diffusion and change}

Single and multiple fused norm diffusion, as discussed above, engages the "stable" quality of norms. However, some accepted norm diffusion mechanisms can also result in intersubjectively acceptable decision-making outcomes beyond merely acceptance or rejection of a fused norm: specifically, by emphasizing the "flexible" aspect of norms, these processes can actually change a norm's contents as it diffuses to new adopters. When norms change or evolve as they diffuse, they change in particular ways: the scope or nature of the problem, the value impacted, or the behavior undertaken as a remedy (Sandholtz, 2008). If one of more of these components is substituted for a new item, the norm's contents have effectively shifted: only certain parts of the original norm have diffused, and a new three-component norm is created out of the combination of those components and whatever has been added by the new adopter.

The simplest reason behind norm variation may lie in the difficulty of determining exactly what the norm in question is. Norms are not always easy to identify: they are “continuous, rather than dichotomous... [and] come in varying strengths (Legro, 1997, p. 33). In addition, as actors operate in conditions of bounded rationality (Jones, 2003) and potential psychological bias (Jervis, 1976; Khong, 1992), hindrances to full information and decisionmaking capacity may result in imperfect identification and choice of norms by potential adopters, creating diffusion outcomes that do not exactly match previous examples.

Norm diffusion implies that norms travel: they are taken out of their original (highly specific) context and applied to a new (highly specific) context. Since norms evolve through 
interaction, normative meaning will inevitably change slightly as context changes from actor to actor (Wiener, 2008, p. 63, 2009). This is the phenomenon of "meaning-in-use." Sandholtz (2008) echoes this argument when he posits that interpreting the existing rules to apply in new, and specific, situations constantly triggers conflicts over interpretation, and resolving these conflicts shifts the nature of the rules themselves, creating a cycle of norm change.

Differences between domestic structures and capacities can sometimes make exact emulation of an existing norm impossible. Domestic context, as Cortell and Davis (2000) argue, accounts for differences in the interpretation of the meaning of norms (value and perhaps problem), and differences in states' compliance with them (behavior). Similarly, variation in the perceived effects of a policy, in both normative and practical terms, is a key difference between the factors motivating states to adopt norms during different phases of the norm life cycle (Finnemore and Sikkink, 1998): during phase 1, states are persuaded that the norm is "the right thing to do" because it resonates with their own identities, either pre-existing or newly redefined. However, states in phase two of the norm life cycle may also perceive an additional positive outcome (such as membership in a group which confers other benefits) which was not relevant for states in phase 1, creating an additional justification for action (value). By phase three, the goal is to avoid sanction rather than gain benefit, either normative or strategic. Therefore, the motivations (and thus publicly stated values) of early adopters and later adopters of the same norm may be different, even if their behaviors are the same.

The same result may occur due to certain processes of norm diffusion such as grafting (Price, 1998) and localization (Acharya, 2004). Because each involves matching a value from a previous adopter or norm entrepreneur with an value already prevalent in the newly adopting state, some flexibility in interpretation is necessary: the local value may not mean exactly the 
same thing as the existing value, but it is conceptually close enough that the terms can be used to refer to the same expected behavior. The resulting final value is a mix of the imported norm and the state's own pre-existing value, but is understood by all parties as comprising a part of the same norm.

Lastly, although framing is helpful in diffusing fused norm components by providing a problem-value interpretation and can lead to the adoption of a fused norm, this is not its only possible effect. Norm entrepreneurs have been known to strategically utilize multiple frames, and to change frames themselves, in order to change states' behaviors (Charnysh, Lloyd and Simmons, 2014). Different frames can lead to the same policy suggestions, and conflicts over interpretation can exist within and across frames (Rein and Schon, 2016). Frames are "multidimensional ideas relevant to a particular policy sphere that serve to organize information, empower certain actors, define goals, and constrain actions" (Bleich, 2002, p. 1064), but, like identity, they need neither be singular nor determinative of a fused norm choice. Framing as a tool of norm diffusion is just as likely to lead to change as to continuity across norm adopters.

\section{Continuity, change, and conceptual structure}

The above processes of norm diffusion which help to explain norm continuity and norm change each focus on one aspect of a norm's dual quality. Each also has implications for how we think about the structure of that variation and of the object itself (the norm). Given a norm's dual nature and the existence of multiple acceptable single norms, there are three major types of variation with respect to norm adoption as an outcome of norm diffusion. The first, fused diffusion of single norms, limits variation, but maintains object continuity. A middle option, which engages questions of choice among a set of fused and stable norms, allows for more variation in adopters' choices while maintaining object continuity, but does not fully explain all 
empirical outcomes. The third, and most flexible, option, that of norm adaptation, allows for variation in both norm contents and state choice, but loses object continuity.

If norm diffusion occurs as a single, combined process for any particular norm, then states encountering a new norm in the international system have only two possible outcomes to their decision-making processes: accept the whole fused norm, or reject it. Adaptation or alternative norm choice may be therefore thought of as rejection, since the existing construction of one or more of the norm's components is rejected in favor of an alternative construction. The norm's contents remain the same. This is the strictest form of both variation and continuity: variation occurs only in terms of yes and no, and the norm's meaning itself does not change, even as actors accept or reject it.

Choice among multiple norms creates the appearance of variation, but it also maintains a certain amount of stability, both with respect to individual norm choices and to the structure of the norm itself. While state outcomes may vary depending on the collection of single norms within a bundle and the decision-making process used to determine which is "most appropriate," each norm within that bundle or framework remains identifiable and constant, and can only be accepted or rejected. Scholars examining the possible choices for different states, or at different time periods, would be able to distinguish the same combinations of problem, value, and behavior that make up each norm in the group. In other words, larger structures (institutions, frameworks, regimes) are reducible to their parts (norms), and each of those parts has only two 
options: accept or reject. ${ }^{8}$ What looks like a lot of variation, then, is actually much more uniform with respect to single objects. ${ }^{9}$

On the other hand, diffusion processes which emphasize the "flexible" quality of norms allow for change in the object as well as variation in outcomes, reflecting the greater variation in the empirical record. However, change in the object itself creates an additional problem: as the norm changes it no longer has the same content as the original; either the problem, value or behavior are now different depending on which actor we examine. We gain variation, but lose object stability. Two scholars studying the same norm at different points in time or space, without knowledge of its evolution, would not identify it as the same object of study.

In conclusion, the processes of norm diffusion expose a conceptual gap: norms are an object of single structure, but dual quality. If norms are regarded as stable, the tripartite construction of norms is traceable throughout the diffusion process, but variation in choice is limited. On the other hand, if norms are flexible, the end result of each diffusion process still contains a norm with its tripartite structure, but the contents of that structure will vary such that the object of the "norm" itself changes from actor to actor. Multiple studies which chronicle both types of norm diffusion exist, so each approach has evidentiary support, but these studies generally do not engage both stability and flexibility, or all three types of outcomes, within the same work. Besides creating a dichotomy in the theoretical record, this leaves the questions of

\footnotetext{
${ }^{8}$ Goertz (1994, p. 225) is particularly critical of regime theory, suggesting that too often scholars accept that norms are embedded in regimes and then go on to study behavior without paying adequate attention to what those norms are, and therefore how they are expected to influence behavior. In other words, the required identification of a regime's embedded norms has not taken place before the behavioral analysis.

${ }^{9}$ Finnemore and Sikkink, and Krasner all note that institutions and regimes may transform. This implies that there is a possibility for the norms contained within them to change over time, but they do not specify whether these are new single norms or modifications of one or more components of the original norms. The processes of norm change and institutional change are certainly linked, but the question of how these norms change remains unanswered by the institution or regimes literatures.
} 
their potential interaction, and the relative prominence of each type the real world, unexplored. In the next section I propose a solution which creates the conceptual space to approach these questions.

\section{A new theoretical construct: Norm clusters}

The analysis above highlighted inconsistencies between the accepted structure of the contemporary international norm and the variety of accepted outcomes of norm diffusion in the real world. One solution to this dilemma is a new conceptual structure: to restructure the concept of the contemporary international norm itself into a looser and less determinate collection of interlocking norm components, which I call a "norm cluster." The following section defines and explores the norm cluster concept, offering an alternative way of understanding indeterminacy and choice in the international system and providing some real-world examples.

A norm cluster is a bounded collection of interrelated specific problems, values and behaviors which are understood to be similar enough that their adopters form a family group (Collier and Mahon, 1993). Within this cluster, problems, values and behaviors may be combined, depending on state context or other factors, into a number of distinct but acceptable combinations of problem, value and behavior. Each combination ("norm") is understood to be an "appropriate" means of addressing the more general problem which motivates norm cluster adoption. However, no state must necessarily directly emulate a predecessor to be seen by others as adopting and implementing the norm cluster. Lastly, although the norm cluster does have boundaries (which components and combinations are included), they are intersubjectively formed, and therefore somewhat malleable based on processes of innovation, discourse and learning conducted by and between relevant actors. 
The concept of a norm cluster retains both the constitutive and constraint functions of traditional norms: while a state is constrained to do something appropriate, it is enabled by the relative freedom of choice within the cluster to determine for itself what constitutes "appropriate behavior" in its own specific context. A certain amount of different meaning-in-use is tolerated by the community as long as a legitimate combination of problem, value and behavior is chosen, and a new component or combination may be legitimized if the community accepts it. Kratochwil describes this decision-making structure as one that is "indeterminate at the level of individual choice but determinate at the level of defining classes of actions" $(2001$, p. 47$) .{ }^{10}$

Switching the unit of analysis from norms to norm components and norm clusters means that principled decision-making may, but need not, embody a single quality of norms: a single norm may be stable for some, and flexible for others, within a range of acceptable variation as defined by the community. Depending on the norm cluster's contents, some states may also choose multiple outcomes while others choose only one. A certain amount of variety in outcomes, given the complexities of the real world, is not only possible but likely. In the meantime, object continuity is preserved since the outcomes are all included possibilities within a larger whole. A norm cluster allows for decision outcomes which are either stable or flexible, either fused or changed, such that each state's options may be individually different, but all can be traced back to the larger object of study. Although some actors will directly adopt an existing fused norm, or choose from a number of existing fused norms, others will innovate, leading to

\footnotetext{
${ }^{10}$ It can also be thought of as similar to Welsh's (2013) "responsibility to consider" with respect to R2P in which options for action must be carefully considered in response to a problem, but no specific behavior is mandated. The difference is that some action must be taken (beyond mere consideration) to be seen as implementing the norm cluster.
} 
change in their individual normative outcome but not change in the larger object. Lastly, some forms of innovation may even alter the boundaries of the norm cluster itself.

\section{Creating a norm cluster}

Norm clusters emerge, grow, and change, just as single norms have been theorized to do, and by using the same diffusion mechanisms. While adopters of a norm cluster may choose outcomes which create either continuity or change, however, it is the latter which enables a norm cluster to exist in the first place. The key to enabling, creating, and evolving a norm cluster and its resulting variety of acceptable value-behavior combinations, as opposed to a single norm or bundle of single norms and the continuity they imply, is the ability of norm components to diffuse separately without engendering sanction. If the link between a single problem, value and behavior is loosened, then the process of diffusion can therefore work separately on each norm component as long as the result is accepted by the community, and the intersubjective understanding of the norm cluster is adjusted to include this new outcome.

This is in contrast to the fused form of diffusion, found with respect to single or multiple norms but also within a norm cluster, in which the content does not change. Although each choice leads to a single (local) norm ${ }^{11}$ with a tripartite structure, these individual choices are assembled from a range of acceptable options rather than diffused from a single absolute. A newly adopting state has a greater wealth of legitimate examples from which to choose and combine specific problem, value and behavior. Previous adopters judge the state's choice as "close enough" and recognize that the new adopter is engaging in "appropriate behavior," and

\footnotetext{
${ }^{11}$ I take the term "local norm" from Acharya (2004), but with an additional meaning: the combination of acceptable norm components chosen for a specific actor at a specific time. They need not be, as Acharya suggests, pre-existing in national society rather than international.
} 
the norm cluster spreads, although specific combinations within it may not diffuse directly from one state to another as a fused unit. ${ }^{12}$

Unfused diffusion leading to acceptable change, and thus the creation of a norm cluster out of a single norm or set of single norms, may occur for a variety of reasons. First, actors at different stages of the diffusion process may be subject to different influences. In their spiral model of human rights norm diffusion, Risse and Sikkink (Risse and Sikkink, 1999) argue that different actors use different diffusion mechanisms over time directed at a single state. If different actors and different processes of socialization are at work throughout a state's socialization process, but are more or less effective at different points, it would suggest that these different actors (and their different diffusion processes) will be more or less effective at diffusing different parts of the norm. This in turn suggests that these different actors may also hold slightly different conceptions of the norm, and that between multiple actors, frames, diffusion mechanisms, and periods of time, the eventual norm adopted may not resemble the norm as any of these other actors understood it.

Second, the literature on implementation and compliance (Checkel 1997, Betts, Orchard 2014) also suggests unfused diffusion: it assumes that the processes of reaching international agreement on norms and the processes of actually implementing them are subject to different influences from different actors. If the domestic actors necessary to create law are different from those who reach international agreement, the diffusion mechanism which worked on one may not

\footnotetext{
${ }^{12}$ It is possible that not every combination from within the cluster, or every attempt to add new components through one of the norm change mechanisms described earlier, will be successful. It is entirely possible that the community will not accept a particular change as appropriate, in which case it would not comprise part of the norm cluster and the state making the change would not be recognized as a norm adopter. Indeed, a norm cluster in which all attempts at evolution were rejected would resemble a single norm or set of single norms. In addition, parties may disagree on whether a change is acceptable, creating indeterminacy in the cluster's exact contents. Empirical evidence suggests that this is rather common.
} 
work on the other. A form of strategic bargaining resembling a two-level game (Putnam, 1988) may take place instead, meaning that two different diffusion mechanisms are at work on the same norm in the same state, coming from potentially different actors and working on potentially different logics.

Third, March and Olsen argue that the logics of appropriateness and consequences may coexist, compete, and complement one another within any single institution that determines rulebased behavior. They offer two hierarchies of logics in which "the logic of appropriateness may be used subject to the constraints of extreme consequences" or, alternatively, that "rules of appropriateness are seen as one of several constraints within which the logic of consequentiality operates" (2008, p. 703). They also point out that the two logics depend on different abilities and resources: to determine what is "right" and to calculate the expected utility of a behavior take different inputs from different actors, following different mechanisms (i.e. persuasion vs. learning). If one actor employs moral argument and the other rational utility calculation, then a state could conceivably agree with the value of the moral arguer and the behavior of the rational arguer. Because both the value and the behavior are already included in the norm cluster (albeit combined with different components), the new combination would only have to be deemed compatible to be accepted as a legitimate expression of the norm cluster.

Separate diffusion of norm components, and their acceptance as legitimate expressions of a common norm cluster, has been demonstrated in the existing record. As an example of a logic of consequences following a logic of appropriateness leading to unfused diffusion, Lloyd, Simmons and Stewart (2011) trace the spread of anti-human trafficking legislation. Global discourse on trafficking has framed the problem in either criminal or victimization terms, reflecting two different interpretations of the problem-value nexus (Charnysh, Lloyd and 
Simmons, 2014). ${ }^{13}$ However, the authors find that the most consistent predictor of the diffusion of anti-trafficking law (behavior) is the level of road linkage with a previously adopting country: they argue that the shifting of direct negative externalities onto a state will cause it to change its policies. In this case, the link between general problem and value may be influenced by any actor in the international system, but behavioral change comes due to the relationship with one's direct neighbor and the more specific problems it creates. Different norm components diffuse via different mechanisms, from different actors, and at different times. Each state's local version of the anti-trafficking norm cluster would then depend on two things: whether the criminalization or human rights frame was more persuasive, and what the specific effects of trafficking were for that state. Several types of domestic legislation which can be grouped into either of the two frames are suggested via the Optional Protocol on Human Trafficking, whose preamble reflects the values of prevention, punishment and protection (United Nations, 2000).

\section{Norm clusters in the real world: Investigating structure}

Examination of some real-world norm clusters which have previously been understood as either single norms or norm sets helps to illuminate the structural differences between the two as well as to demonstrate the increased analytical utility of the norm cluster concept. Empirically, norm clusters consisting of a single value and a relatively narrow problem, but a number of different behaviors, are quite common. Indeed, this is how norms scholars often explain domestic variation in the implementation of norms which comes from variations in pre-existing domestic structures or practices. The norm embodied in the Non-Proliferation Treaty (NPT) (United

\footnotetext{
${ }^{13}$ If trafficking is a criminal activity, it is a problem for societies which value the rule of law and security; if its victims are most important, then it is a problem for societies which value human rights. Either frame could diffuse from any actor in the global system, but the authors find that the increase in support for addressing human trafficking at the UN has been through a process of accommodating both frames, rather than the triumph of just one, again suggesting multiple values and behaviors within a norm cluster.
} 
Nations, 1968) is a prime example of this structure: avoiding nuclear war is the overarching value for all adopters. ${ }^{14}$ The problem is nuclear technology, which could enable nuclear war. However, depending on whether states have nuclear technology, either military or civilian, the expected behaviors for this norm are quite different. The norm cluster in the NPT looks like this:

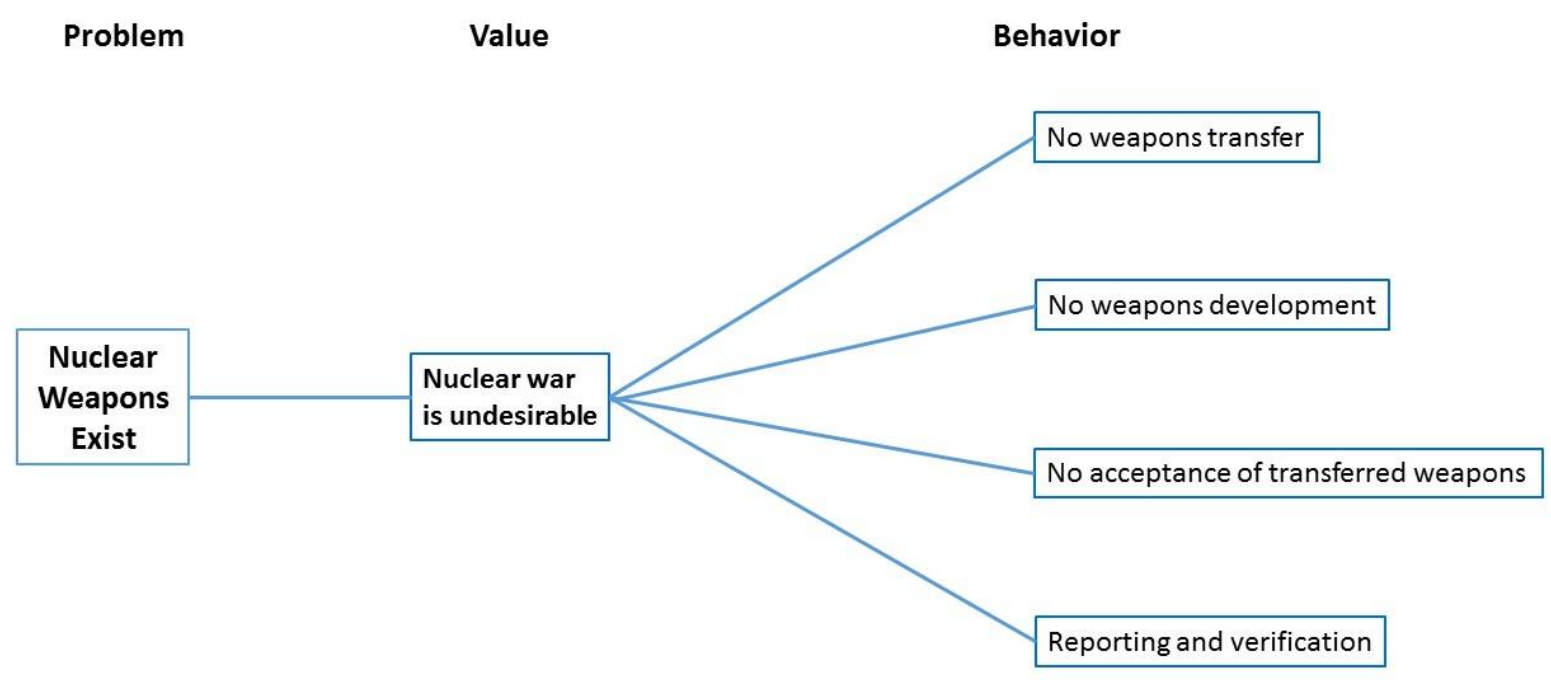

Figure 2: Norm cluster of the Nuclear Non-Proliferation Treaty.(United Nations, 1968)

States which have nuclear weapons are expected not to transfer them (Article 1), and states without are expected to neither accept nor develop them (Article 2). All states are required to put in place verification, reporting and monitoring procedures to prove that they are following through on the other behaviors (Article 3). Thus, each state has different behavioral obligations based on its specific domestic context, although the value and the general problem remain the same. All states are required to report, but the existing nuclear powers have different specific behavioral obligations than do non-nuclear states. States which ratify the NPT adopt the same

\footnotetext{
14 This problem also applies to the norm of non-use of nuclear weapons, although no such treaty exists. The norms are related, but not identical. The NPT does not forbid states to use nuclear weapons. Non-proliferation does not mean non-use, and non-use does not necessarily imply non-proliferation. In addition, non-use includes use not in war, suggesting more values for non-use than for non-proliferation.
} 
non-proliferation "norm" but, in so doing, they agree to carry out potentially varying behaviors depending on their particular circumstances. ${ }^{15}$

The opposite configuration of a norm cluster occurs as well: states may justify a single behavior with reference to multiple related, but distinct, values. This may be an attempt to please multiple audiences invested in the problem, thus gaining consensus for the adoption of the single behavior, or it may be the result of variations in framing by different norm entrepreneurs, or both. It is not uncommon to see multiple clauses in the preamble of a law stating a number of different justifications for the same piece of legislation, which may in the end be quite specific in terms of institutional choice. In addition, the choice of value may be instructive in the particular design of those institutions, as certain design aspects are emphasized or ignored in the pursuit of a particular goal.

\footnotetext{
${ }^{15}$ A clause exists in the NPT which is not part of the non-proliferation norm cluster: States Parties to the NPT are allowed and encouraged to transfer peaceful nuclear technology. This clause is included in order to incorporate, rather than override, law created by a separate treaty on peaceful nuclear technology transfers. Additionally, while some refer to the NPT as setting up a non-proliferation regime, this includes a complex set of rules and decisionmaking procedures to implement the non-proliferation norm cluster, including specific transparency and reporting requirements, what counts as banned vs. dual-use technologies, and so forth. The NPT regime expands beyond the non-proliferation norm cluster.
} 


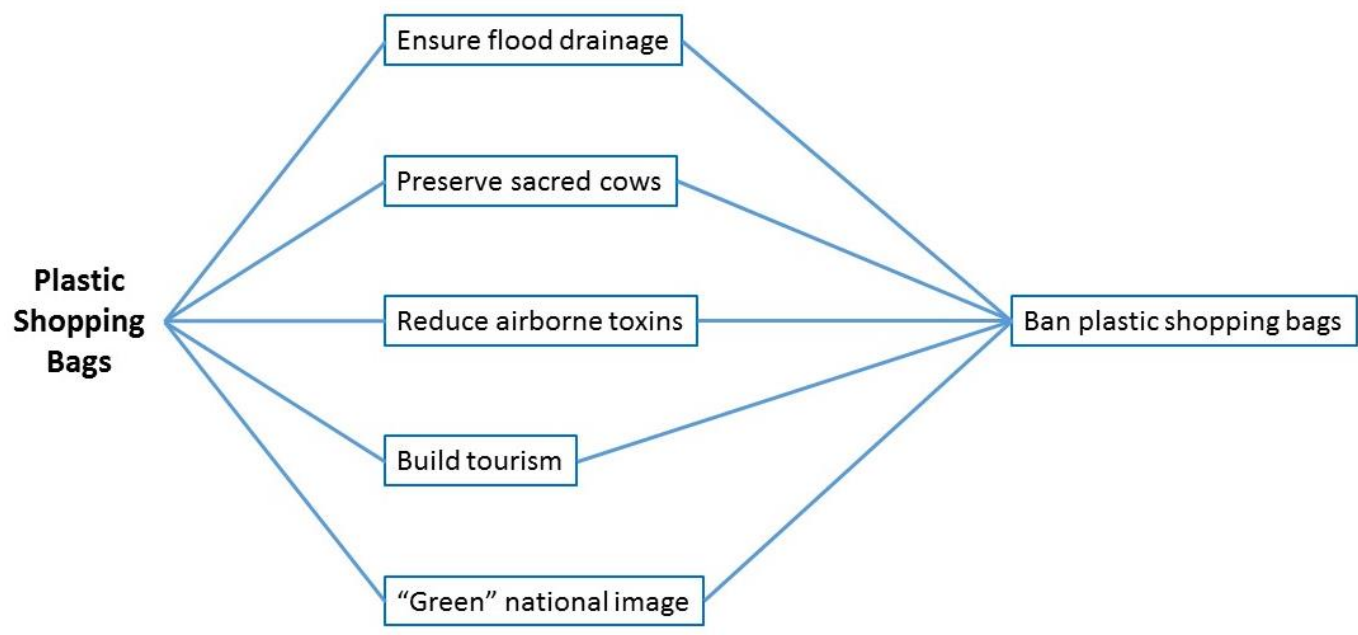

Figure 3: The anti-plastic-bag norm cluster, as identified by Clapp and Swanston (2009).

An example is the development of the anti-plastic-shopping-bag norm. As Clapp and Swanston (2009) argue, the prohibition or restriction of plastic shopping bags initially followed a pattern similar to the phenomenon of multiple realizability, in which very different but vaguely environmental justifications (suggesting values) were given by the early-adopting states. The bags block floodwater drains (Bangladesh, flood management), pose a threat to sacred cows (India, animal protection), release toxins from incineration (Taiwan, air quality), harm the tourist industry focused on natural wonders (South Africa, preservation of the natural environment), and finally hamper the country's "green" image (Ireland, environment as national identity). While all are recognizable as generally related - environmental protection - not every state would have agreed with the appropriateness of all the particular values within the set: for example, only India has sacred cows. In addition, there was no particular attempt at persuasion or strategic framing from one state to another; environmental NGOs within each country were primarily responsible for pushing the norm and thus for generating discourse, but did not take their arguments beyond national borders. Today, the anti-plastic-bag norm cluster, including problem, value and 
behavior, has both diffused to new adopters (moving it beyond multiple realizability) and reached a point of intersubjective understanding where newly adopting states do not always explicitly state their specific reasons for the ban, and merely issuing guidelines through their (general value) Environment departments (Ondieki, 2017).

The above examples were of norm clusters that scholars have typically thought of as single norms: one problem, and either one behavior or one value. However, because norms do not exist in a vacuum and often interact with one another in sets, bundles, frameworks, or other structures, the norm cluster concept also provides an alternative way of understanding the linkages between the three types of norm components within this larger group. While theories of policy differentiation suggest continuity within a fixed group of options, the norm cluster allows for both continuity and change, and for the creation of many distinct combinations of problem, ideation and behavior, offering both greater choice and greater agency for adopting states.

For example, the field of Transitional Justice (TJ), traditionally thought of as a set of norms rather than a single norm, has in fact evolved into a broad and highly varied norm cluster, generally addressing severe human rights violations (the "problem" writ large). However, these violations may come from several different sources: treatment of minorities by otherwise democratic states, practices of authoritarian governments, civil conflict or war, and grave breaches of international humanitarian law such as genocide or crimes against humanity (Crocker, 1999). Scholars and practitioners of TJ have identified a number of different "justice" values impacted (rule of law, accountability reconciliation, peace, restoration of victims' human rights, democracy, truth, etc.) and a range of state-based TJ practices meant to restore them (trials, commissions, lustrations and vetting practices, reparations, and amnesties) (see for example Transitional Justice Research Collaborative, no date; Crocker, 2004; Clark, 2008; Daly, 
2008; Olsen, Payne and Reiter, 2010; Forsythe, 2011; Tiemessen, 2011; Balasco, 2013; Sikkink and Kim, 2013). As with the examples above, these may be combined by individual actors into formulations that resemble traditional single norms or norm clusters which include adaptations beyond an original single norm. But because they are interlinked and related to a larger general problem, examining several smaller items in isolation still gives an incomplete picture of the field. Were all these components able to be combined with each other, for the greatest possible variation in norm outcomes, the norm cluster for the whole field of transitional justice might instead look like this:

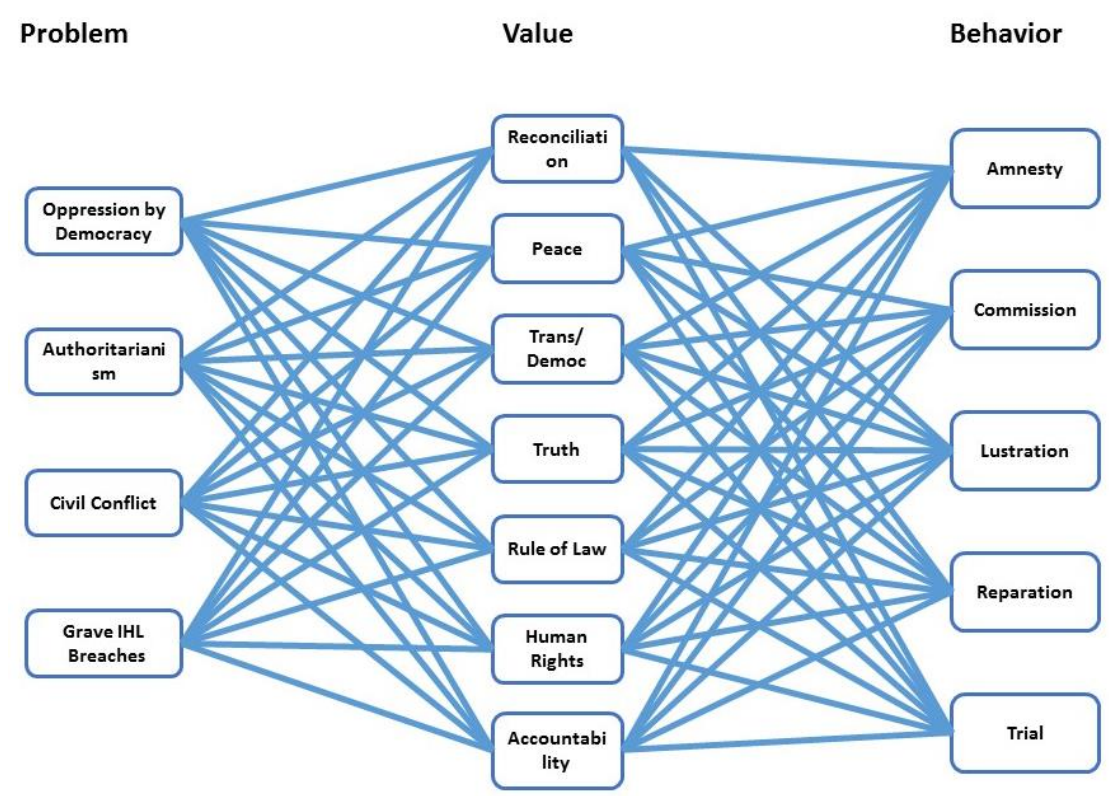

Figure 2: A visualization of the potential transitional justice norm cluster.

The TJ norm cluster is, in structure, much larger and more complex than the two examples discussed above. There are three major reasons: First, because a single state may have more than one of these problems at the same time, even committed by the same actors - for example, an authoritarian government engaged in a civil war commits crimes against humanity providing separate policy responses for each (based on single fused norms) may not effectively 
address the combined weight of those problems on a state's core values. Not only are multiple complementary responses necessary to address multiple values and problems, but they are not always easily separated out into single three-component norms. A state may implement one or several "single" norms, such as lustrations for rule of law in post-communist states and trials for accountability for war crimes, but examples such as "Truth and Reconciliation Commissions," with broad mandates to address multiple specific sources of human rights violations, are also common. ${ }^{16}$

Second, some of these accepted combinations (when applied to particular actors or in conjunction with other combinations) may actually conflict with one another, such as amnesties (for peace, reconciliation or transition) versus trials (for accountability, truth, or rule of law). At least one scholar has called the multiple goals of TJ "irreconcilable" (Leebaw, 2008), and the practical effects of some policies cancel out the opportunity to employ others. Third, not all possible combinations from within the cluster are likely to provide a plausible causal story: amnesties are not thought to lead to truth, for example, since perpetrators would have no incentive to disclose what happened. ${ }^{17}$

As states decide how to approach their own histories, different actors may argue about and compromise over each single component as well as their potential combinations. Single behaviors have been justified with multiple value statements ("Truth and Reconciliation Commission") and applied to multiple problems (amnesties for formerly exiled political opposition as well as the outgoing ruling junta), creating confusion as to the content of each

\footnotetext{
${ }^{16}$ South Africa's TRC is arguably the most famous, but there have been several more with this designation since its creation. See (Ben-Josef Hirsch, 2013).

${ }^{17}$ South Africa is, again, a notable exception: amnesty was offered only in exchange for the truth, while incomplete truth-telling left perpetrators potentially subject to criminal prosecution. The formula has not been repeated elsewhere.
} 
specific norm within the set. While many scholars have identified individual norms from within the TJ cluster, only some responses are seen as fixed and universal, such as trials for perpetrators of genocide (United Nations, 1948), while most responses are highly localized and diverse combinations of problem, value, and behavior from within the cluster (Orentlicher, 2007).

In a norm cluster, rather than a set of fixed norms, both continuity and change exist within a single issue area, making both state decision-making and academic study inherently difficult without a way to understand their interaction at a conceptual level. What the norm cluster offers, therefore, is a way to link all of these pieces of the puzzle together: how to reconcile the existence of continuity and change with respect to the whole group, to explore the potential for norm complementarity as well as conflict, and to relate multiple potential influences on diffusion and actors' own agency in normative development.

\section{Conclusion: Implications for diffusion and evolution}

A norm cluster represents an expanded space within which multiple combinations of problems, ideations and behaviors result in an intersubjectively acceptable set of solutions, and a group of principled actors whose decisions are understood to be "close enough" to one another that they may be studied as a family group, or category. By creating a conceptual space in which possibilities for continuity and change may interact with one another, where variation and stability co-exist, and where intersubjective meaning is at once generally set and specifically fluid, the norm cluster allows for the interaction of two sets of norm diffusion theory which have previously exited across a conceptual gap. The concept also raises several important questions and avenues for research, both theoretical and empirical. 
First, this article has so far presented norm clusters in a static format: as they might appear at a particular point in time, and to multiple actors making choices at that point. However, because norm clusters diffuse, a complete study of norm cluster diffusion and evolution necessarily includes the passage of time. The social construction of norms implies an ongoing process of constitution based on activity, and therefore leaves open the possibility of change in that shared understanding. When researching a norm over its life cycle, then, "it is crucial to establish whether or not the condition of 'being shared' holds" (Wiener, 2007, p. 58). This implies that a critical task for scholars researching norms empirically is to determine whether actors actually have coalesced in their understandings of the contents of a norm cluster: at what points, and for which actors, are the included values, behaviors, and combinations fixed versus flexible, and just how flexible they are. Especially as concerns the acceptance of new components and combinations or the removal of previously accepted ones, fuzzy-set analysis may be a useful methodological approach (Goertz, 2005; Ragin and Pennings, 2005).

The second set of major questions concerns the adopting state: how to choose continuity or change in the specific combination of components chosen when adopting a norm cluster. In other words, does the adopting state share the common understanding of the norm cluster's contents, or not? Without a defined decision-making structure, states are confronted with multiple options, each with its own set of costs, benefits, and risks. In addition, depending on the structure of the norm cluster in question, the range of possible options already accepted as legitimate may be large or small, further complicating decision-making due to the number of existing precedents. The identification of specific strategies for choice, or practices and discourses of justification and innovation, may help to explain how and why norm clusters 
evolve in particular patterns and whether states will make decisions according to consistent indicators or not. ${ }^{18}$

Third, more work remains to be done on the community which "shares" this common interpretation of the contents of a norm cluster, and how it interacts with individual cluster adopters. Because norms are intersubjective, the construction and use of a norm cluster is necessarily dependent both on the implementing actor and the community which accepts or rejects that actor's decisions. Adding a new ideation or behavior to a norm cluster is akin to amending the "prevailing rules" regarding what is considered appropriate behavior and what is not. As Coleman argues, “An action that breaks previously accepted understandings of international rules can still be legitimate if the international community is persuaded to accept either a new rule or a new interpretation of existing rules" $(2007,47)$. While the processes of convincing the community of the appropriateness of a new component or combination may be the same as those used to convince the community about new single norms (bargaining, persuasion, learning, argumentation, socialization, coercion, etc.), they may be applied in varying ways degrees across different parts of the cluster, and to different parts of the community. This is the process of determining what "counts as' within the intersubjective frameworks held by that collectivity" (Ruggie 1998, 860). ${ }^{19}$ But the makeup and dynamics of that collectivity for any particular norm cluster - who holds veto power, or critical influence, over which actors, what

\footnotetext{
18 This has particularly important implications for the quantitative analysis of norm clusters; if the reasons why states choose either particular combinations are not consistent, then quantitative analyses of the characteristics of norm adopters will not be useful for predicting adoption, implementation, or success. In addition, norm clusters with a high rate of variation and a history of innovation and change may be confronted with multiple issues concerning the size and makeup of the case universe over time.

${ }^{19}$ This may be particularly true in a pre-formalization stage, which Betts and Orchard refer to as "principle norms" (2014, p. 14) but it is not restricted to this stage. Scholars generally assume that formalization (via a treaty) "fixes" definitions and obligations, but the existence of treaty reservations, particularly, are seen by various parties either as an accommodation of diversity which allows for greater treaty adherence or as derogations of the norms contained within the treaties which weaken their overall strength (Neumayer, 2007).
} 
discursive and practical mechanisms convince it to accept change, and whether critical mass is required in all cases - remains unclear.

Lastly, when taken together, the choices of norm adopters to pursue continuity or change in the contents of a norm cluster and the processes by which the community does or does not accept proposed changes creates "feedback loops" (Tiemessen 2011, Job, Shesterinina 2014) or “cycles of change" (Sandholtz 2008, Sandholtz, Stiles 2009) which may strengthen, weaken, or fundamentally alter the contents of a given norm cluster and its likelihood of future adoption or adherence. Indeed, if a community rejects all attempts to change the contents of a norm, it remains in its singular, fused form and resembles norms as we have traditionally understood them. Of particular interest to practitioners is the "deep but narrow" versus "broad but shallow" understanding of treaty obligations, in which agreements with more options or fewer necessary actions may be more widely adopted, but with less favorable results per adopting state.(Gilligan, 2004)

Analyzing international norms from the perspective of conceptual structure, namely norm components and norm clusters, represents a small but important addition to the existing theory, and vast literature, on international norms. It supplies a piece of the larger puzzle regarding what norms are: one which reconciles the two sets of theoretical traditions prevalent in the field. The first treats norms as stable objects which structure the behavior of actors, and the second understands them as malleable objects which are influenced by actors. The norm cluster concept manages the agent-structure problem with respect to a single object of study. This allows for the accumulation of knowledge on how the two sides of the problem relate and interact, and may lead to a wealth of new theory on how norms diffuse, evolve, and affect the world. 
References

Acharya, A. (2004) 'How Ideas Spread: Whose Norms Matter? Norm Localization and Institutional Change in Asian Regionalism', International Organization, 58(2), pp. 239-275. doi: 10.1017/S0020818304582024.

Balasco, L. M. (2013) 'The Transitions of Transitional Justice: Mapping the Waves From Promise to Practice', Journal of Human Rights, 12(2). doi: 10.1080/14754835.2013.784858.

Ben-Josef Hirsch, M. (2013) 'Ideational change and the emergence of the international norm of truth and reconciliation commissions', European Journal of International Relations, 20(3), pp. 810-833. doi: 10.1177/1354066113484344.

Betts, A. and Orchard, P. (eds) (2014) Implementation and World Politics: How International Norms Change Practice. Oxford University Press.

Bleich, E. (2002) 'Integrating Ideas into Policy-Making Analysis: Frames and Race Policies in Britain and France', Comparative Political Studies, 35(9), pp. 1054-1076. doi: $10.1177 / 001041402237506$.

Carpenter, R. C. (2007) 'Setting the advocacy agenda: Theorizing issue emergence and nonemergence in transnational advocacy networks', International Studies Quarterly, 51(1), pp. 99-120. doi: 10.1111/j.1468-2478.2007.00441.x.

Charnysh, V., Lloyd, P. and Simmons, B. (2014) 'Frames and consensus formation in international relations: The case of trafficking in persons', European Journal of International Relations, pp. 1-29. doi: 10.1177/1354066114530173.

Chayes, A. and Chayes, A. H. (1995) The New Sovereignty: Compliance with International Regulatory Agreements. Harvard University Press.

Checkel, J. (1997) 'International Norms and Domestic Politics: Bridging the Rationalist-Constructivist Divide', European Journal of International Relations, 3(4), pp. 473-495. doi: 10.1177/1354066197003004003.

Checkel, J. T. (2001) 'The Europeanization of Citizenship?', in Cowles, M. G., Caporaso, J., and Risse, T. (eds) Transforming Europe: Europeanization and Domestic Change. Cornell University Press, pp. 180-197.

Clapp, J. and Swanston, L. (2009) 'Doing away with plastic shopping bags: international patterns of norm emergence and policy implementation', Environmental Politics, 18(3), pp. 315332. doi: 10.1080/09644010902823717.

Clark, J. N. (2008) 'The three Rs: retributive justice, restorative justice, and reconciliation', Contemporary Justice Review, 11(4), pp. 331-350. doi: $10.1080 / 10282580802482603$.

Collier, D. and Mahon, J. E. (1993) 'Conceptual "stretching” revisited: Adapting categories in comparative analysis’, American Political Science Review, 87(4), pp. 845-855.

Cortell, A. P. and Davis, J. W. (2000) 'Understanding the Domestic Impact of International Norms: A Research Agenda', International Studies Review, 2(1), pp. 65-87.

Crocker, D. A. (1999) 'Reckoning with Past Wrongs: A Normative Framework', Ethics 
\& International Affairs, 13(1), pp. 43-64.

Daly, E. (2008) 'Truth Skepticism: An Inquiry into the Value of Truth in Times of Transition', The International Journal of Transitional Justice, 2(March), pp. 23-41. doi: 10.1093/ijtj/ijn004.

Donnelly, J. (1986) 'International human rights: a regime analysis', International Organization, 40(3), pp. 599-642.

Fearon, J. D. (1999) What Is Identity (As We Now Use the Word)?, Department of Political Science (Stanford University). doi: http://w.

Finnemore, M. and Sikkink, K. (1998) 'International Norm Dynamics and Political Change', International Or, 52(4), pp. 887-917.

Forsythe, D. P. (2011) 'Forum: Transitional justice: The quest for theory to inform policy', International Studies Review, 13(3), pp. 554-578. doi: 10.1111/j.14682486.2011.01016.x.

Gilligan, M. J. (2004) 'Is There a Broader-Deeper Trade-off in International Multilateral Agreements?', International Organization, 58(3), pp. 459-484. doi: $10.1017 /$ S0020818304583029.

Goertz, G. (1994) Contexts of International Politics. Cambridge University Press.

Goertz, G. (2003) International Norms and Decision Making: A Punctuated Equilibrium Model - Gary Goertz - Google Books. Rowman \& Littlefield.

Goertz, G. (2005) 'Two-Level Theories and Fuzzy-Set Analysis', Sociological Methods \& Research, 33(4), pp. 497-538. doi: 10.1177/0049124104266128.

Holzinger, K. and Schimmelfennig, F. (2012) 'Differentiated integration in the European Union: Many concepts, sparse theory, few data', Journal of European Public Policy. Routledge, 19(2), pp. 292-305. doi: 10.1080/13501763.2012.641747.

Hurrell, A. and Macdonald, T. (2012) 'Norms and Ethics in International Relations', in Simmons, B. A., Carlsnaes, W., and Risse, T. (eds) Handbook of International Relations. Sage Publications, pp. 57-84. doi: 10.4135/9781848608290.n7.

Jepperson, R. L., Wendt, A. and Katzenstein, P. J. (1996) 'Norms, Identity and Culture in National Security', in Katzenstein, P. J. (ed.) The culture of national security: Norms and identity in world politics. Columbia University Press, pp. 33-75.

Jervis, R. (1976) Perception and Misperception in International Politics. Princeton University Press.

Jones, B. (2003) 'Bounded rationality and political science: Lessons from public administration and public policy', Journal of Public Administration Research and Theory.

Khong, Y. (1992) Analogies at War: Korea, Munich, Dien Bien Phu, and the Vietnam Decisions of 1965.

Krasner, S. D. (1983) International Regimes. Cornell University Press.

Kratochwil, F. (2001) 'How Do Norms Matter?', in Byers, M. (ed.) The Role of Law in International Politics: Essays in International Relations and International Law. Oxford 
University Press, Incorporated, p. 35.

Lebow, R. N. (2016) National Identities and International Relations. Cambridge University Press.

Leebaw, B. A. (2008) 'The Irreconcilable Goals of Transitional Justice', Human Rights Quarterly, 30(1), pp. 95-118. doi: 10.1353/hrq.2008.0014.

Legro, J. (1997) 'Which norms matter? Revisiting the "failure" of internationalism', International Organization.

Leuffen, D., Rittberger, B. and Schimmelfennig, F. (2012) Differentiated Integration: Explaining Variation in the European Union. Palgrave MacMillan.

March, J. G. and Olsen, J. P. (2008) 'The Logic of Appropriateness', in Goodin, R. E., Moran, M., and Rein, M. (eds) The Oxford Handbook of Public Policy, p. 689.

Neumayer, E. (2007) 'Qualified Ratification: Explaining Reservations to International Human Rights Treaties', The Journal of Legal Studies, 36(2), pp. 397-429. doi: 10.1086/511894.

Olsen, T. D., Payne, L. A. and Reiter, A. G. (2010) Transitional Justice in balance: Comparing processes, weighing efficacy. U.S. Institute of Peace Press.

Ondieki, E. (2017) 'Plastic bags now banned', Daily Nation (Kenya), 15 March.

Orentlicher, D. F. (2007) “"Settling Accounts” Revisited: Reconciling Global Norms with Local Agency', The International Journal of Transitional Justice, 1(1), pp. 10-22. doi: 10.1093/ijtj/ijm010.

Payne, R. (2001) 'Persuasion, Frames and Norm Construction', European Journal of International Relations, 7(1), pp. 37-61. doi: 0803973233.

Price, R. (1998) 'Reversing the Gun Sights: Transnational Civil Society Targets Land Mines', International Organization, 52(3), pp. 613-644. doi: 10.1162/002081898550671.

Putnam, R. D. (1988) 'Politics and Domestic Diplomacy the logic of two-level games', International Organization, 42(3), pp. 427-460.

Ragin, C. C. and Pennings, P. (2005) 'Fuzzy Sets and Social Research', Sociological Methods \& Research, 33(4), pp. 423-430. doi: 10.1177/0049124105274499.

Rein, M. and Schon, D. (2016) 'The Argumentative Turn in Policy Analysis', 10. doi: 10.1007/978-3-319-30549-3.

Risse, T. (2000) “"Let's Argue!': Communicative action in world politics', International Organization, 54(1), pp. 1-40.

Risse, T. and Sikkink, K. (1999) The socialization of international human rights norms into domestic practices: introduction, The Power of Human Rights - International Norms and Domestic Change. doi: 10.2307/20049553. Press.

Sandholtz, W. (2007) Prohibiting Plunder: How Norms Change. Oxford University

Sandholtz, W. (2008) 'Dynamics of International Norm Change: Rules against Wartime Plunder', European Journal of International Relations, 14(1), pp. 101-131. doi: 10.1177/1354066107087766. 
Schimmelfennig, F. (2014) 'EU enlargement and differentiated integration: discrimination or equal treatment?', Journal of European Public Policy, 21(5), pp. 681-698. doi: 10.1080/13501763.2014.897744.

Sikkink, K. and Kim, H. J. (2013) 'The Justice Cascade: The Origins and Effectiveness of Prosecutions of Human Rights Violations', Annual Review of Law and Social Science, 9(1). doi: 10.1146/annurev-lawsocsci-102612-133956.

Stone, D. A. (1989) 'Causal Stories and the Formation of Policy Agendas', Political Science Quarterly, 104(2), pp. 281-300.

Tiemessen, A. (2011) The International Normative Structure of Transitional Justice. University of British Columbia.

Transitional Justice Research Collaborative (no date) Transitional Justice Collaborative. Available at: https://www.transitionaljusticedata.com/ (Accessed: 24 April 2017).

United Nations (1948) Convention on the Prevention and Punishment of the Crime of Genocide, U.N. Treaty Series no. 1021.

United Nations (1968) Treaty on the Non-Proliferation of Nuclear Weapons (NPT).

United Nations (2000) Protocol to Prevent, Suppress and Punish Trafficking in Persons, Especially Women and Children, supplementing the United Nations Convention against Transnational Organized Crime.

Welsh, J. M. (2013) 'Norm Contestation and the Responsibility to Protect', Global Responsibility to Protect. Leiden: Martinus Nijhoff Publishers, 5(4), pp. 365-396. doi: 10.1163/1875984X-00504002.

Wendt, A. (1999) Social Theory of International Politics. Cambridge University Press.

Wiener, A. (2007) 'The Dual Quality of Norms and Governance beyond the State: Sociological and Normative Approaches to "Interaction", Critical Review of International Social and Political Philosophy, 10(1), pp. 47-69. doi: 10.1080/13698230601122412.

Wiener, A. (2008) The Invisible Constitution of Politics. Cambridge University Press.

Wiener, A. (2009) 'Enacting Meaning-in-Use: Qualitative Research on Norms and International Relations', Review of International Studies. NEW YORK: CAMBRIDGE UNIV PRESS, 35(1), pp. 175-193. doi: 10.1017/S0260210509008377.

Wiener, A. (2014) A Theory of Contestation. Springer Berlin Heidelberg. 